\title{
Coexpression of intercellular adhesion molecule-1 and class I major histocompatibility complex antigens on hepatocyte membrane in chronic viral hepatitis
}

\author{
C M Chu, Y F Liaw
}

\begin{abstract}
Aims-To evaluate the role of hepatocyte expression of leucocyte adhesion molecules and major histocompatibility complex (MHC) antigens in the pathogenesis of chronic viral hepatitis.

Methods-The expression of intercellular adhesion molecule 1 (ICAM-1), lymphocyte function associated antigen 3 (LFA3), and MHC class I and II antigens on hepatocyte membrane in relation to the histological and biochemical activities was studied in patients with chronic $B$ hepatitis, chronic persistent hepatitis (CPH) $\mathbf{n}=23$; chronic active hepatitis (CAH) $\mathbf{n}=20$; chronic $D$ hepatitis (CAH) $n=6$; and chronic non-A, non-B hepatitis (CPH $n=4$, CAM $n=6$ ). Six of the latter were hepatitis $C$ virus antibody positive.

Results-In chronic B hepatitis ICAM-1 and MHC-I were expressed significantly more in patients with CAH than in those with CPH ( $<<0.001)$, while the expression of LFA-3 and MHC-II showed no significant difference, irrespective of serum HBeAg or hepatitis B virus DNA. Similar findings were noted in non- $A$, non-B hepatitis. Regardless of the viral aetiology, patients with CAH had a significantly higher degree of ICAM-1 and MHC-I expression than LFA-3 ( $p<0.001$ $v$ ICAM-1 and MHC-I, respectively) and MHC-II (p < 0.001 $v$ ICAM-1 and MHC-

lymphocyte killing requires interaction between effector cytotoxic $\mathrm{T}$ lymphocytes and target cells. ${ }^{6}$ The specificity of the cellular immune response is determined by the $T$ cell receptors interacting with the antigen and the major histocompatibility complex (MHC) antigens, ${ }^{7}$ but other T cell and target cell surface molecules are required before $T$ cell adhesion can occur. ${ }^{89}$ Two leucocyte adhesion pathways have been characterised that are essential for $T$ cell adhesion to several other cell types. The first includes the lymphocyte function associated antigen 1 (LFA-1), present on almost all leucocytes ${ }^{10}$ and its major target cell ligand, the intercellular adhesion molecule 1 (ICAM-1), expressed on many cell types. The second adhesion pathway involves the interaction of the $T$ cell surface molecule CD2 with its specific ligand, the lymphocyte function associated antigen 3 (LFA-3), which is expressed on a wide variety of cells. ${ }^{112}$ Recent evidence suggests that these two leucocyte adhesion pathways are important not only in regulating antigen independent adhesion but also in delivering costimulatory signals to amplify $\mathrm{T}$ cell activation. $^{13-15}$ It seems that in chronic HBV infection the expression of ICAM-1 and LFA-3 adhesion molecules by hepatocytes in inflammatory sites may be an important initiator for hepatocyte $T$ lymphocyte interaction; the expression of MHC antigens may be more important in postadherence antigenic recognition.
\end{abstract} I, respectively) expression. Those with CPH showed little or no difference in the expression of these four molecules. Furthermore, serum ALT values positively correlated with the hepatocyte expression of ICAM-1 (p < 0.001) and MHC-I $(p<0.001)$, but not LFA-3 $(p>0.05)$ and MHC-II (p > 0.05).

Conclusions-In chronic viral hepatitis hepatocyte expression of ICAM-1 and MHC-I might be important for immunosurveillance against virally infected hepatocytes, while the expression of LFA-3 and MHC-II does not seem to have a role in the pathogenesis of chronic viral hepatitis.

(F Clin Pathol 1993;46:1004-1008)

It has been suggested that hepatitis $B$ virus (HBV) is not directly cytopathic and that liver injury is mediated by cytotoxic $\mathrm{T}$ lymphocytes. $^{1-5}$ The generation of cytotoxic $T$

\section{Methods}

Fifty nine patients with chronic viral hepatitis confirmed histopathologically were studied. All had increased serum alanine aminotransferase values for more than six months before the histological examination, and drugs or alcohol misuse was excluded as a likely cause. Their detailed clinical and laboratory data are listed in the table. Forty three patients were hepatitis B surface antigen ( $\mathrm{HBsAg}$ ) positive and antibody against hepatitis delta virus (anti-HDV) negative. HBV DNA was positive in 12 hepatitis $\mathrm{Be}$ antigen ( $\mathrm{HBeAg}$ ) positive patients with chronic persistent hepatitis $(\mathrm{CPH}), 14 \mathrm{HBeAg}$ positive patients with chronic active hepatitis (CAH), and two anti$\mathrm{HBe}$ positive patients with $\mathrm{CAH}$. Six patients had chronic D hepatitis as they were HBsAg and anti-HDV positive and had hepatitis delta antigen (HDAg) detectable in the liver. Ten patients were $\mathrm{HBsAg}$ negative and were presumed to have chronic non-A, non-B 
Clinical and laboratory data of patients studied

\begin{tabular}{lccccc}
\hline Category & $\begin{array}{l}\text { Cases } \\
(n)\end{array}$ & $\begin{array}{l}\text { Age* } \\
(y r)\end{array}$ & $\begin{array}{l}\text { Sex } \\
(M: F)\end{array}$ & $\begin{array}{c}\text { AST (IU/l) } \\
(n<40)\end{array}$ & $\begin{array}{l}{ }^{*} A L T(I U / l)^{*} \\
(n<40)\end{array}$ \\
\hline $\begin{array}{l}\text { Chronic B hepatitis } \\
\text { HBeAg positive CPH }\end{array}$ & 14 & $24(2)$ & $10: 4$ & $61(5)$ & $115(23)$ \\
HBeAg positive CAH & 16 & $27(2)$ & $13: 3$ & $128(15)$ & $268(36)$ \\
anti-HBe positive CAH & 4 & $33(5)$ & $4: 0$ & $142(39)$ & $303(130)$ \\
$\quad \begin{array}{l}\text { anti-HBe positive CPH } \\
\text { Chronic D hepatitis }\end{array}$ & 9 & $36(3)$ & $8: 1$ & $31(5)$ & $46(5)$ \\
$\quad \begin{array}{l}\text { Anti-HBe positive CAH } \\
\text { Chronic non-A, non-B hepatitist }\end{array}$ & 6 & $35(3)$ & $6: 0$ & $131(30)$ & $261(64)$ \\
CPH & 4 & $29(4)$ & $2: 2$ & $41(6)$ & $55(7)$ \\
CAH & 6 & $31(3)$ & $3: 3$ & $129(34)$ & $266(72)$ \\
\hline
\end{tabular}

$\mathrm{CPH}$ : Chronic persistent hepatitis; $\mathrm{CAH}$ : Chronic active hepatitis.

*Data are mean (SEM).

t6 were antibody against hepatitis $C$ virus positive.
(NANB) hepatitis. Of these, six were seropositive for antibodies against hepatitis $C$ virus (anti-HCV).

Serum HBsAg, $\mathrm{HBeAg}$, and anti-HDV were assayed using radioimmunoassay kits (Ausria-II, HBe-RIA and anti-delta, Abbott Laboratories, Chicago, Illinois). Serum antiHCV was assayed using a second generation enzyme immunoassay with synthetic peptides from both structural and non-structural regions of $\mathrm{HCV}$ (UBI HCV EIA, United Biochemical, New York). Serum HBV DNA was assayed by spot hybridisation with ${ }^{32} \mathrm{P}-$ labelled cloned HBV-DNA, and hepatocyte expression of HDAg was studied by direct immunofluorescence using fluorescein isothiocyanate-labelled anti-delta, as reported before. ${ }^{16}$

Liver specimens were obtained by percutaneous needle biopsy with a Menghini needle. Fragments of specimens were snap frozen in liquid nitrogen cooled isopentane and stored at $-70^{\circ} \mathrm{C}$ until use. Samples of the same biopsy specimens were also fixed in $10 \%$ formaldehyde and embedded in paraffin wax for routine histological diagnosis. Cryostat sections $(5 \mu \mathrm{m})$ were dried overnight at room temperature and fixed in carbon tetrachloride at $4^{\circ} \mathrm{C}$ for 10 minutes, followed by extensive washing with phosphate buffered saline $(\mathrm{pH}$ $7 \cdot 2$ ) before staining. The expression of LFA1, CD2, ICAM-1, LFA-3, MHC class I and class II antigens in liver was studied using a three step immunoalkaline-phosphatase (APAAP) method. Briefly, sections were incubated for 45 minutes at room temperature with the following mouse monoclonal antibodies: Dako-CD11a (Dakopatts, working dilution 1 in 50) reacting with the $a$-chain of LFA-1; Dako-T11 (Dakopatts, working dilution 1 in 50) specific for CD2; antibodies against CD54 and CD58 (Immunotech, SA, working dilution 1 in 50) specific for ICAM-1 and LFA-3, respectively, Dako-HLA-ABC (Dakopatts, working dilution 1 in 50) specific for MHC class I antigens; and Dako-HLADR (Dakopatts, working dilution 1 in 50) specific for MHC class II antigens. After a wash in TRIS-buffered saline (TBS), sections were reincubated for 30 minutes with rabbit anti-mouse immunoglobulin (Dako; working dilution 1 in 20). After a further wash in TBS, APAAP immune complexes (Dako; working dilution 1 in 30 ) were applied to the sections for 30 minutes. The last two steps were repeated for 10 minutes each and finally the alkaline phosphatase reaction was developed using the hexazotised new fuchsin procedure. Endogenous alkaline phosphatase activity was blocked by adding levamisole to the substrate solution at a concentration of $1 \mathrm{mmol} / \mathrm{l}$. Control tests consisted of omission of the primary antibody or substitution with non-immune mouse immunoglobulins (Dako) and incubation with alkaline phosphatase substrate alone.

The expression of ICAM-1, LFA-3, MHC class I and class II antigens on the hepatocyte membrane was scored on a scale of 0 to $3+:(0)$ undetectable, when they were present on the sinusoidal lining cells but absent on the hepatocyte membrane; $(1+)$ positive staining on the hepatocyte membrane in only small clusters $(<10 \%)$ of hepatocytes; $(2+)$ positive staining on the hepatocyte membrane in $10-50 \%$ of hepatocytes; and $(3+)$ positive staining on the hepatocyte membrane in more than half of the hepatocytes with honeycomb appearance.

Results were analysed using Wilcoxon's non-parametric rank sum test and Spearman's rank correlation test.

\section{Results}

LFA-1 was expressed on most of the inflammatory infiltrates as well as on the sinusoidal lining cells. Serial sections showed CD2 expression on the same cells positive for LFA-1. ICAM-1, LFA-3, MHC class I and class II antigens were expressed on the sinusoidal lining cells and on a variable proportion of mononuclear inflammatory cells throughout the portal areas and lobular parenchyma.

Among 43 patients with chronic type B hepatitis, the expression of ICAM-1 on the hepatocyte membrane was similar to that of MHC class I antigens. The degree of ICAM1 expression was significantly higher than that of LFA-3 ( $<<0.001)$ and MHC class II antigens $(p<0.001)$, as was the expression of MHC class I antigens ( $p<0.001 v$ LFA-3 and MHC class II antigens, respectively). The expression of ICAM-1 and MHC class I antigens on the hepatocyte membrane correlated well with the site and the extent of the inflammatory infiltrates in liver tissue as well as the histological activity. Figure 1 shows that patients with $\mathrm{CAH}$ had a significantly higher degree of ICAM-1 and MHC class I antigen expression than those with $\mathrm{CPH}$, irrespective of serum $\mathrm{HBeAg}$ or HBV-DNA. An example of ICAM-1 expression on hepatocyte membrane in patients with $\mathrm{CPH} v \mathrm{CAH}$ is shown in fig 2 . In contrast, the expression of LFA-3 and MHC class II antigens showed no significant difference between patients with $\mathrm{CAH}$ and those with CPH. Similar observations were seen in patients with chronic NANB hepatitis. In general, regardless of the viral aetiology, patients with $\mathrm{CAH}$ had a significantly higher degree of expression of ICAM-1 and MHC class I antigens than 
Figure 1 Expression of ICAM-1, LFA-3, MHC-I and $M H C-I I$ on the hepatocyte membrane in chronic hepatitis type $B$, $D$, and non- $A$, non- $B$ (NANB). Hepatocyte expression of ICAM-1, $L F A-3, M H C-I$ and MHC-II antigens is semiquantitatively scored on a scale of 0 to $3+$ CPH: chronic persistent hepatitis; CAH: chronic active hepatitis.

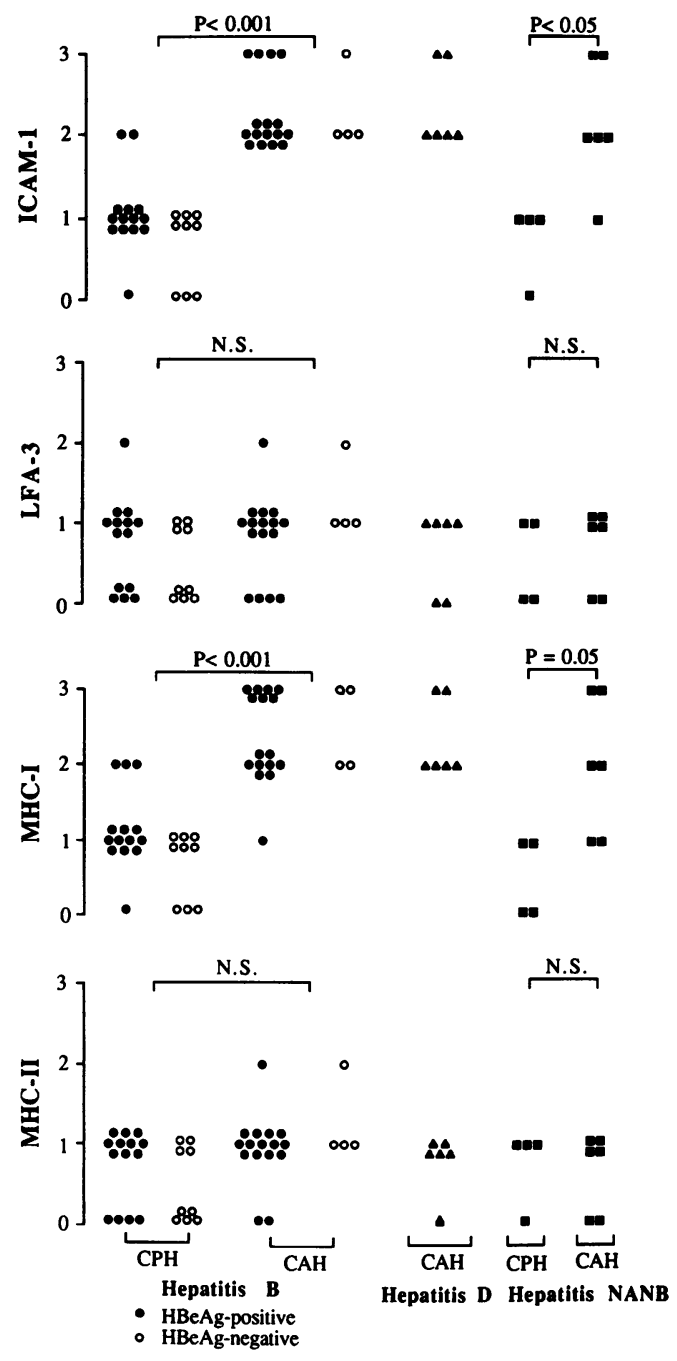

that of LFA-3 (p < 0.001 $v$ ICAM-1 and MHC class I antigens, respectively) and MHC class II antigens ( $p<0.001 v$ ICAM-1 and MHC class I antigens, respectively), while patients with $\mathrm{CPH}$ had little or no difference in the expression of these four molecules.

Among a total of 59 controls with chronic viral hepatitis, ALT values correlated positively with the expression of ICAM-1 $(p<0.001)$ and MHC class I antigens ( $p<0.001)$ on the hepatocyte membrane, but not with that of LFA-3 ( $>0.05)$ and MHC class II antigens ( $p>0.05$ ) (fig 3 ).

\section{Discussion}

The expression of ICAM-1 and MHC class I antigens, but not LFA-3 and MHC class II antigens, on the hepatocyte membrane correlated significantly with the histological and biochemical activities in chronic HBV infection (figs 1 and 3 ). These findings suggest that hepatocyte expression of ICAM-1 and MHC class I antigens might be important for immune surveillance against virus infected hepatocytes in chronic HBV infection, while hepatocyte expression of LFA-3 and MHC class II antigens does not seem to have a role in the pathogenesis of chronic B hepatitis. Similar findings were found in patients with chronic C and D hepatitis (figs 1 and 3). The pathogenesis of liver cell damage in chronic $\mathrm{HCV}$ and HDV infection remains unknown, but recent studies have shown that there was a prominent CD8 positive $T$ lymphocyte infiltration in the area of liver cell necrosis in chronic $\mathrm{C}$ and D hepatitis, ${ }^{17}{ }^{18}$ similar to those observed in chronic $B$ hepatitis. ${ }^{23}$ The present findings thus suggest that an immunological mechanism might also be involved in the pathogenesis of chronic $C$ and $D$ hepatitis, though the possibility of the direct cytopathic effect of $\mathrm{HCV}$ and HDV still cannot be excluded.

Previous studies have shown enhanced expression of ICAM-1 ${ }^{19-22}$ as well as MHC class I antigens ${ }^{23-29}$ on the target structures in a number of inflammatory liver diseases. The mechanisms leading to their enhanced expression, however, remain to be elucidated. The present results indicated that hepatocyte expression of ICAM-1 and MHC class I antigens in chronic $B$ hepatitis did not seem to be upmodulated by active $\mathrm{HBV}$ replication itself. Studies on cultured cells have shown that both ICAM-1 and MHC class I antigen expression is induced on many cell types in response to inflammatory lymphokines, such as interleukin-1, tumour necrosis factor and $\gamma$-interferon. ${ }^{30-34}$ The observation of an enhanced expression of ICAM-1 and MHC class I antigens simultaneously on the hepatocyte membrane at the site of necroinflammation and active cellular infiltration is thus consistent with the presence of inflammatory lymphokines at such sites, and with the induction of ICAM-1 and MHC class I antigens by such mediators. It is therefore suggested that the release of the inflammatory lymphokines by virus sensitised $\mathrm{T}$ lymphocytes around the area of virally infected hepatocytes will enhance hepatocyte expression of ICAM-1 and MHC class I antigens. The upmodulated expression of ICAM-1 on the hepatocyte membrane might facilitate movement of, and possibly "guiding", more $T$ lymphocytes toward virally infected hepatocytes, but it might also serve as an important initiator for hepatocyte/T lymphocyte interaction. The latter then will maintain a broad area of approximation between cells so that MHC class I antigen-restricted, $T$ lymphocyte mediated killing of infected hepatocytes can occur.

Coexpression of ICAM-1 and MHC class II antigens by hepatocytes, which correlated positively with the site and extent of the inflammatory infiltrates, has recently been reported in chronic B hepatitis by Volpes et $a l .{ }^{20}$ In keeping with many previous observations, however, ${ }^{24} 27-29$ our study showed that hepatocyte expression of MHC class II antigens was negligible, if any, regardless of liver inflammatory activity in chronic HBV infection. As many inflammatory lymphokines, including interferon, are potent inducers for cell surface expression of both class $I$ and class II MHC antigens on many cell types, ${ }^{35-37}$ it remains unclear why the hepatocyte expression of MHC class II antigens is minimal at 
Figure 2 In chronic persistent hepatitis, the expression ICAM-1 on the hepatocyte membrane is (A) negative or $(B)$ positive only in small clusters of hepatocytes (large arrow heads). Note strong staining of ICAM-1 on the sinusoidal lining cells (small arrows). In chronic active hepatitis, in addition to the staining on the sinusoidal lining cells (small arrows), the expression of ICAM-1 on the hepatocyte membrane is (C) prominent in the periportal hepatocytes

(large arrow heads) or (D) diffuse over the whole liver parenchyma with honeycomb appearance. $P$ indicates portal tract.
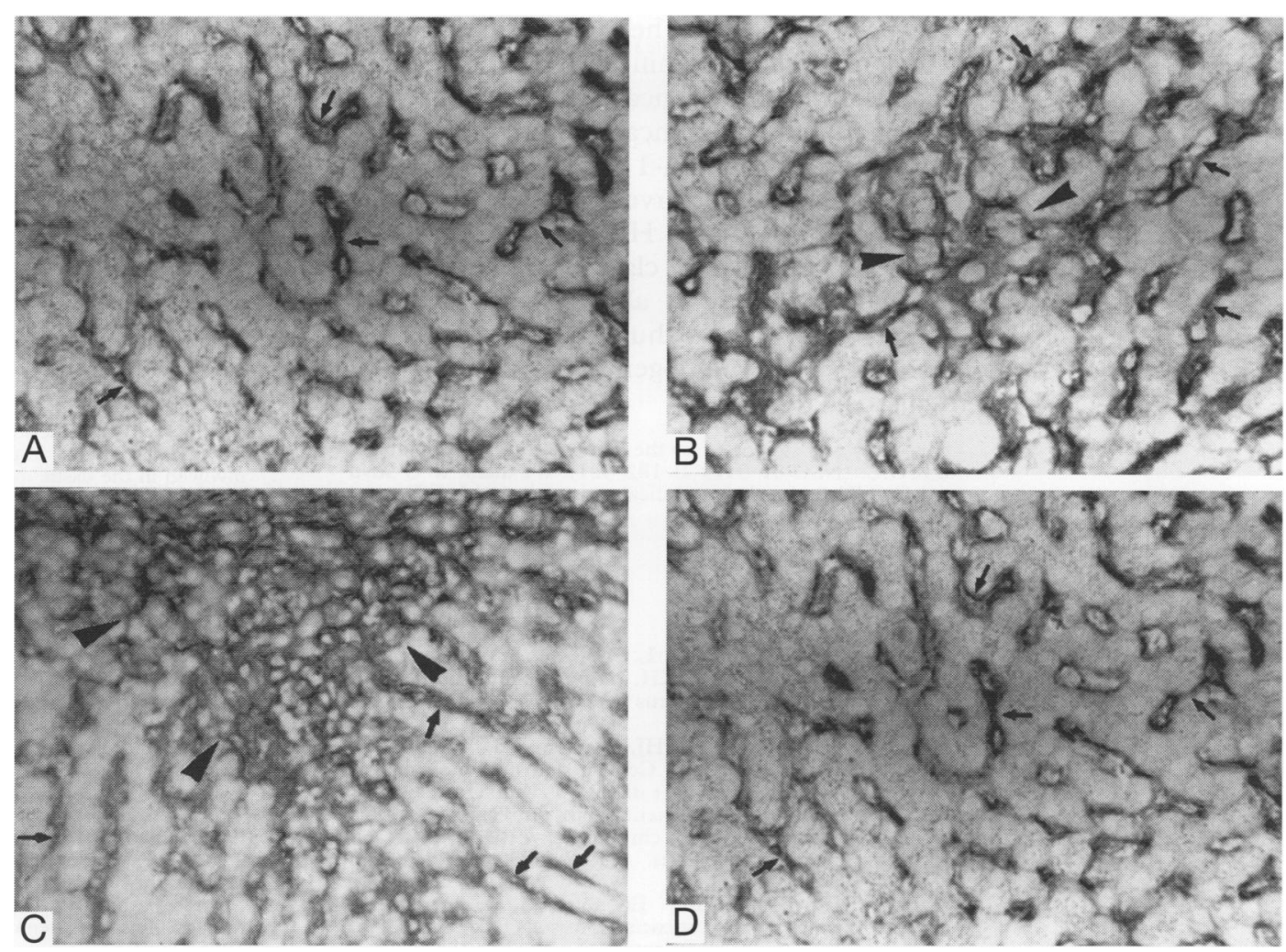

the site of inflammatory response, where there is increased expression of MHC class I antigens. Of note is that interferon treatment in chronic B or C hepatitis enhanced hepatocyte expression of MHC class I antigens with little or no effect on the expression of MHC class II antigens. ${ }^{27}{ }^{37}$ One of the possibilities is that the effects of interferon or other inflammatory lymphokines on cell surface expression of MHC antigens depend on the type and origin of the cells. ${ }^{38}$ Further studies are needed to investigate the in vitro effect of different inflammatory lymphokines on hepatocyte expression of $\mathrm{MHC}$ antigens.

Although most inflammatory infiltrates express CD2 molecules in chronic viral hepatitis, the present study showed that LFA3 , the ligand for CD2, was usually expressed only in a small cluster of hepatocytes, regardless of the biochemical or histological activity. These findings argue against the CD2/LFA-3 leucocyte adhesion pathway in the pathogenesis of chronic viral hepatitis. ${ }^{2139}$ This discrepancy may be because of the differences in the choice of antisera, tissue manipulation, or staining protocols. Of note is that the regulation of cell surface expression of LFA-3 is different from that of ICAM-1. Studies on certain cell type have shown that LFA-3 expression was specifically induced by interleukin-4, but not by other inflammatory lymphokines, including interleukin-1 and $\gamma$-interferon. ${ }^{40}$ It remains unclear whether interleukin-4 is produced locally by the inflammatory infiltrates in chronic viral hepatitis. In addition, further study on the effect of various lymphokines on hepatocyte expression of LFA-3 is also mandatory.

In conclusion, in chronic viral hepatitis ICAM-1 and MHC class I antigens are

Figure 3 Correlation of serum ALT values with hepatocyte membrane expression of
ICAM-1, LFA-3, MHC-I and MHC-II in chronic viral hepatitis. Hepatocyte expression of ICAM-1, LFA-3, MHC-I and MHC-II antigens is semiquantitatively scored on a scale of 0 to $3+$. rs indicates correlation coefficient using Spearman's rank correlation coefficient. 
coexpressed on the hepatocyte membrane, which correlated significantly with the biochemical and histological results. These data indicated the significance of hepatocyte expression of ICAM-1 and MHC class I antigen in immune surveillance against virally infected hepatocytes. Hepatocyte expression of LFA-3 and MHC class II antigens correlated little or not at all with inflammatory activity in liver, and thus did not seem to be involved in the pathogenesis of chronic viral hepatitis.

This study was supported by the National Science of Council of R.O.C. (NSC 81-0419-B-182-521). We thank W C Shyu and $C$ C Wang for their technical assistance and $L F$ Yao for her secretarial help.

1 Thomas HC, Montano L, Goodall A, deKoning R, Oladapo J, Wiedman KH. Immunological mechanisms in chronic hepatitis B virus infection. Hepatology 1982;2: $116 \mathrm{~S}-21 \mathrm{~S}$.

2 Eggink HF, Houthoff HJ, Huitema S, Wolters G, Poppema S, Gips CH. Cellular and humoral immune reactions in chronic liver disease. I. lymphocyte subsets in liver biopsies of patients with untreated idiopathic in liver biopsies of patients with untreated idiopathic autoimmune hepatitis, chronic active hepatitis $\mathbf{B}$ and primar

3 Page GR, Rieber EP, Eisenburg J, Hoffmann $R$ Involvement of cytotoxic/suppressor $\mathrm{T}$-cell subset in liver tissue injury of patients with acute and chronic live disease. Gastroenterology 1983;85:657-62.

4 Eddleston ALWF, Mondelli M, Mieli-Vergani G, Williams R. Lymphocyte cytotoxicity to autologous hepatocytes in chronic hepatitis $\mathbf{B}$ virus infection. Hepatology 1982;2:122S-7S

5 Pignatelli M, Waters J, Lever A, Iwarson S, Gerety R, Thomas HC. Cytotoxic T cell responses to the nucleocapsid proteins of HBV in chronic hepatitis: Evidence capsid proteins of $\mathrm{HBV}$ in chronic hepatitis: Evidence that antibody modulation

6 Shaw S, Luce GEG, Quinones R, Gress RE, Springer TA Sanders ME. Two antigen-independent adhesion pathways used by human cytotoxic T-cell clones. Nature 1986;323:262-4.

7 Meuer SC, Acuto O, Hercend T, Schlossman SF, Reinherz EL. The human T-cell receptor. Ann Rev Immunol 1984;2:23-50.

8 Shaw S, Luce GEG. The lymphocyte function-associated antigen (LFA)-1 and CD2/LFA-3 pathway of antigenindependent human $\mathrm{T}$ cell Adhesion. $₹$ Immunol 1987 ; 139:1037-45.

9 Springer TA, Dustin ML, Kishimoto TK, Marlin SD The lymphocyte function associated LFA-1, CD2 and LFA-3 molecules: Cell adhesion receptors of the immune system. Ann Rev Immunol 1987;5:233-52

10 Kurzinger K, Reynolds T, Germain SD, Springer TA. A novel lymphocyte function-associated antigen (LFA-1) Cellular distribution, quantitative expression and structure. F Immunol 1981;127:596-602

11 Kreusky AM, Sanchez-Madrid F, Robbins E, Nagy J, Springer TA, Burakoff SJ. The functional significance, distribution and structure of LFA-1, LFA-2 and LFA-3: Cell surface antigens associated with CTL-target interaction. $₹$ Immunol 1983;131:611-6.

12 Selvaraj P, Plunkett MJ, Dustin ML, Sanders ME, Shaw $S$, Springer TA. T lymphocyte glycoprotein CD2 binds to the cell surface ligand LFA-3. Nature $1987 ; 326$ : to the

13 Wacholtz MC, Patel SS, Lipsky PE. Leukocyte functionassociated antigen 1 is an activation molecule for human T cells. $\mathcal{F}$ Exp Med 1989;170:431-48

14 Bierer BA, Peterson A, Gorga J, Hermann SH, Burakoff SJ. Synergistic T cell activation via the physiological ligands for $\mathrm{CD} 2$ and the $\mathrm{T}$ cell receptor. $\mathcal{F}$ Exp Med 1988 168:1145-56.

15 Moingeon P, Chang HC, Wallner BP, Stebbins C, Frey $A Z$, Reinherz EL. CD2-mediated adhesion facilitates T lymphocyte antigen recognition function. Nature 1989; 339:312-4.

16 Chu CM, Liaw YF. Intrahepatic expression of pre-S1 and pre-S2 antigens in chronic hepatitis B virus infection in pre-sion to hepatitis B virus replication and hepatitis relation to hepatitis B virus replication and
delta virus superinfection. Gut 1992;33:1544-8.

17 Onji M, Kikuchi T, Kumon I, et al. Intrahepatic lympho- cyte subpopulations and HLA class I antigen expression by hepatocytes in chronic hepatitis C. Hepatogastroenterol 1992;39:340-3.

18 Chu CM, Liaw YF. Studies on the composition of the mononuclear cell infiltrates in liver from patients with chronic active delta hepatitis. Hepatology 1989;10: 911-5.

19 Adams DH, Hubscher SG, Shaw J, Rothlein $R$, Neuberger JM. Intercellular adhesion molecule on liver allografts during rejection. Lancet 1989;ii:1122-5.

20 Volpes R, Van den Oord JJ, Desmet VJ. Hepatic expression of intercellular adhesion molecule-1 (ICAM-1) in viral hepatitis B. Hepatology 1990;12:148-54.

21 Malizia G, Dino O, Pisa R, et al. Expression of leukocyte adhesion molecules in the liver of patients with chronic hepatitis B virus infection. Gastroenterology 1991;100: 749-55.

22 Burra P, Hubscher SG, Shaw J, Elias E, Adams DH. Is the intercellular adhesion molecule-1/leukocyte function associated antigen 1 pathway of leukocyte adhesion involved in the tissue damage of alcoholic hepatitis? Gut 1992;33:268-71.

23 Barbatis C, Woods J, Morton JA, Fleming KA, McMichael A, O'OMcGee G. Immunohistochemical analysis of HLA (A, B, C) antigens in liver disease using a monoclonal antibody. Gut 1981;22:985-91.

24 Fukusato T, Gerber MA, Thung SN, Ferrone $S$, Schaffiner F. Expression of HLA class I antigens on hepatocytes in liver disease. Am $\mathcal{f}$ Pathol 1986;123: 264-70.

25 Franco A, Barnaba V, Natali PG, Balsano C, Musca A Balsano F. Expression of class I and class II major histocompatibility antigens on human hepatocytes. Hepatology 1988;8:449-54.

26 Nagafuchi Y, Hobbs KEF, Thomas HC, Scheuer PJ. Expression of $\beta_{2}$-microglobulin on hepatocytes after liver transplantation. Lancet $1985 ; \mathrm{i}: 551-4$.

27 Pignatelli $M$, Waters J, Brown D, et al. HLA class I antigens on the hepatocyte membrane during recovery from acute hepatitis $B$ virus infection and during interferon therapy in chronic hepatitis B virus infection. Hepatology 1986;6:349-53.

28 Ballardini G, Bianchi FB, Mirakian R, Fallani M, Pisi E, Bottazzo GF. HLA-A, B, C, HLA-D/DR and HLAD/DQ expression on unfixed liver biopsy sections from patients with chronic liver disease. Clin Exp Immunol 1987;70:35-46.

29 Chu CM, Shyu WC, Kuo RW, Liaw YF HIA class I antigen display on hepatocyte membrane in chronic hepatitis B virus infection its role in the pathogenesic
chronic type B hepatitis. Hepatology $1988 ; 8: 712-7$.

30 Dustin ML, Rothlein R, Bhan AK, Dinarello CA, Springer TA. Induction by IL-1 and interferon- $\gamma$ : Tissue distribution, biochemistry, and function of a natural adherence molecule (ICAM-1). F Immunol 1986;137: 245-53.

31 Rothlein R, Czajkowski M, O'Neill MM, Marlin SD, Mainolfi E, Merluzzi VJ. Induction of intercellular adhesion molecule 1 on primary and continuous cell lines by proinflammatory cytokines. $\mathcal{f}$ Immunol 1988;141:1665-9.

32 Basham TY, Bourgeade MF, Creasey AA, Merigan TC. Interferon increases HLA synthesis in melanoma cells: interferon-resistant and sensitive

33 Collins T, Lapierre LA, Fiers W, Strominger JL, Pober JS. Recombinant human tumor necrosis factor increases mRNA levels and surface expression of HLA-A, B, antigens in vascular endothelial cells and dermal fibroblasts in vitro. Proc Natl Acad Sci USA 1986;83:446-50.

34 Peizesmaiser K, Scheurich P, Schluter C, Kronke M. Tumor necrosis factor enhances HLA-A, B, C and HLA-DR gene expression in human tumor cells. $\mathcal{F}$ Immunol 1987;138:975-80.

35 Durandy A, Virelizier, Griscelli C. Enhancement by interferon of membrane HLA antigens in patients with combined immunodeficiency with defective HLA combined immunodeficiency with defective

36 Halloran PF, Wadgymar A, Autenried P. The regulation of expression of major histocompatibility complex products. Transplantation 1986;41:413-20.

37 Pescarmona E, Gandin C, Monardo F, et al. MHC-class I and class II antigen expression in anti-HCV positive chronic hepatitis: effect of IFN-alpha and IFN-alph plus ursodeoxycholic acid. $f$ Hepatol 1992;17: 37 .

38 Billard C, Febus D, Kolb JP, et al. Qualitative differences in effects of recombinant $a-, \beta$ - and $\gamma$-interferons in human peripheral blood leukocytes in vitro. Ann Inst Pasteur/Immunol 1986;137c:259-72.

39 Autschbach F, Meuer SC, Moebius U, et al. Hepatocellular expression of lymphocyte function-associated antigen 3 in chronic hepatitis. Hepatology 1991;14: antigen $223-30$.

40 Rousset $\mathrm{F}$, Billand $\mathrm{M}$, Blanchard $\mathrm{D}$, et al. IL-4 induces LFA-1 and LFA-3 expression on Burkitt's lymphoma cell lines. F Immunol 1989;143:1490-8. 
brief descriptions of geographical distribution, morphology, and life cycle.

Section 2 contains over 250 colour photographs covering a wide range of parasite morphology, pathology (including stained sections), and clinical pictures with captions on the facing page. Although the overall quality of the photographs is excellent, I was disappointed to see a lack of size markers on all but a handful. In the clinical laboratory size is of vital importance for identifying ova and cysts.

The third section contains black and white electron micrographs, radiographs, and other illustrations, separated from the colour section for reasons of economy. This does not detract from the atlas in any way, and indeed some of the scanning electron microscopic images are quite breathtaking. I would, however, like to have seen some indication of size on the photographs.

This atlas has a spacious and orderly feel to it, and I am impressed by the overall quality. Clinical microbiologists, particularly those in training, will find it useful.

Atlas of Ovarian Tumors. L Deligdisch, A Altchek, CJ Cohen. (Pp 182; £94.) Igaku-Shoin. 1994. ISBN 0-89640-240-1.

This sumptuously produced atlas is subdivided into two main sections with three chapters devoted to "clinical aspects" and seven chapters allocated to "pathology". This strategy may be convenient in a multiauthor text, but it has resulted in a clinical section which is pathologically naive and a pathological section impoverished by the paucity of clinicopathological correlation.

The wide-ranging introductory chapter, which covers epidemiology, genetics, molecular biology, early diagnosis, and screening for ovarian cancer, provides a useful overview of the subject, although the emphasis placed on ultrasonography is excessive. The two ensuing chapters, both rather lengthy and repetitive, are devoted to management of ovarian carcinoma and nonepithelial tumours, respectively.

The pathology section comprises four chapters devoted to primary epithelial neoplasms including a whole chapter on the interesting but controversial subject of ovarian intraepithelial neoplasia. Other chapters deal with sex cord-stromal tumours, germ cell tumours, and metastatic tumours. This section is well illustrated with adequate photomicrographs and gross photographs of excellent quality. However, many entities are skimpily and uncritically described with no attempt to evaluate the taxonomic overenthusiasm displayed by recent authors in this field. On the other hand, many rare but well established entities are not included. An even more serious drawback for a book aimed at the practising histopathologist is the lack of consideration given to possible differential diagnoses.

In conclusion, this new atlas is unlikely to fulfil the need for a comprehensive, authoritative, and up to date reference text on ovarian neoplasms. It cannot be recommended as a bench book for the reporting room.

\section{Notices}

\section{Postgraduate course: \\ Current concepts in surgical pathology}

November 14-18 1994

\section{Massachusetts General Hospital,} Harvard Medical School

This course is designed for pathologists at resident and practitioner levels. It will provide an in-depth review of diagnostic surgical pathology with emphasis on morphological features, newly recognised entities, and new techniques, presented by the faculty of the Department of Pathology, Massachusetts General Hospital. Instruction will be primarily by lecture, but will also include discussion periods. Each participant will receive a comprehensive course syllabus.

The course has category 1 accreditation for about 35 hours CME credit by the American Medical Association. The fee for the course is $\$ 785.00$ (residents and fellows $\$ 575 \cdot 00$ ).

For further information contact: Department of Continuing Education, Harvard Medical School, 25 Shattuck Street, Boston, MA 02115 USA (Tel: 0101 (617) 432 1525).

\section{Update on Cerebrovascular Pathology}

Thursday 8 December 1994 (one-day) to be held at The Royal College of Pathologists, 2 Carlton House Terrace, London SW1Y 5AF.

The meeting is open to members and non-members of the College. Further details and application forms can be obtained from the Scientific Meetings Officer, RCPath, 2 Carlton House Terrace, London SW1Y 5AF (Tel: 0719305862 ext: 24/26).

\section{Cytopathology for histopathologists} Northwick Park Hospital

30 January-3 February 1995

This is an intensive course in cytopathology suitable for candidates preparing for the MRCPath examination in histopathology, and for established histopathologists requiring revision. It is given by the Department of Cellular Pathology, Northwick Park Hospital (Dr Elizabeth A Hudson) and the Department of Cytopathology, St Mary's Hospital Medical School, University of London (Professor Dulcie Coleman).

The programme will consist of lectures, microscopy sessions, and discussions. Topics will include cytopathology of the cervix, urine, the respiratory tract, serous effusions and fine needle aspiration cytology of breast and other sites. The course is limited to 30 participants. The course fee is $£ 300$ excluding accommodation.

Applications and enquiries should be made to: Dr Elizabeth Hudson, Department of Cellular Pathology, Northwick Park Hospital, Harrow, Middlesex HA1 3UJ (Tel: 081-869 3312).

\section{Corrections}

F Clin Pathol 1994;47:205-8; Tillyer et al. The title of the correspondence should read "zinc protoporphyrin assays in patients with $a$ and $\beta$ thalassaemia trait." The title at present implies that zinc assays were performed which was not the case.

In paragraph 2 , the second sentence should read ". . . not only were the drugs causing substantial interference extremely unlikely in the outpatient and general practice population we studied, ...". Paragraph 3 second sentence should read "...Paul and Brumfitt's is $15 \mu \mathrm{mol} / \mathrm{mol}$ haem lower."

DR ML TILLYER

Estimation of haemoglobin concentrations using spectrophotometric tests. $\mathcal{f}$ Clin Pathol 1994;47:681.

The name of the author was given incorrectly as J Larner rather than AJ Larner. ANDREW J LARNER

f Clin Pathol 1993;46:1116-9. (Darjee R, Gibb AP. Serological Investigation into the association between Streptococcus bovis and colonic cancer.) The methods section refers to "NCTC10449 (Enterococcus fecalis), but this should read ATCC19433 (Enterococcus fecalis). NCTC10449 is in fact the reference number of the type strain of $S$ mutans.

AP GIBB

Increased pentane and carbon disulfide in the breath of patients with schizophrenia f Clin Pathol 1993;46:861-4. The concentrations of pentane and carbon disulfide were reported incorrectly. All values of pentane should be multiplied $\times 50$; all values of carbon disulfide $\times 0.05$. The statistical analyses and conclusions of the paper are not affected by these corrections.

MICHAEL PHILLIPS

Chu CM, Liaw YF. Coexpression of intercellular adhesion molecules and class I major histocompatibility compression antigens on hepatocyte membrane in chronic viral hepatitis. I Clin Pathol 1993;46: 1004-8. The correct version of fig $2 \mathrm{D}$ is reproduced below.

CHIA-MING CHU

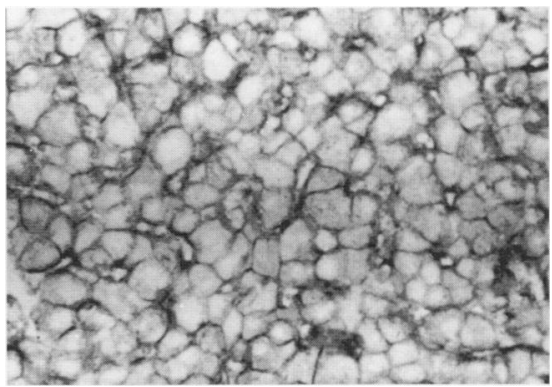

